\title{
Morphology Completion Status
}

National Cancer Institute

\section{Source}

National Cancer Institute. Morphology Completion Status. NCI Thesaurus. Code

C117616.

A term used to describe the state or condition of the completeness of the morphology data. 